\title{
Several Times Daily
}

National Cancer Institute

\section{Source}

National Cancer Institute. Several Times Daily. NCI Thesaurus. Code C118856.

Scheduled or occurring at a frequency of several times per day. 